\title{
INTERGRATIVE HEALTH CARE METHOD BASED ON COMBINED COMPLEMENTARY MEDICAL PRACTICES: REHABILITATIVE ACUPUNCTURE, HOMEOPATHY AND CHIROPRACTIC.
}

\section{1,4* María Esperanza Rodríguez-van Lier, ${ }^{2}$ Luis Manuel Hernández Simón, ${ }^{3}$ Rosa Estela López Gómez and ${ }^{2}$ Ignacio Peón Escalante}

\author{
${ }^{1}$ ESIME, SEPI, Ingeniería de Sistemas IPN, México City \& Sección de Acupuntura, Universidad Estatal del Valle de \\ Ecatepec, Estado de México ${ }^{2}$ ESIME, SEPI, Ingeniería de Sistemas IPN, México City lmhernan10@yahoo.com.mx \\ ${ }^{3}$ Sección de Acupuntura, Universidad Estatal del Valle de Ecatepec, Estado de México edunevestela@ yahoo.com.mx \\ ${ }^{4}$ ESIME, SEPI, Ingeniería de Sistemas IPN, México City ignaciopeon@gmail.com ${ }^{5}$ Universidad Estatal del Valle de \\ Ecatepec, Av. Central esq. Leona Vicario s/n, Valle Anáhuac, $2^{\mathrm{a}}$ secc. C.P. 55210, Ecatepec de Morelos, Estado de \\ México, México \\ *E-mail: rodriguezvanlier@yahoo.com.mx
}

\begin{abstract}
Background: There are various models of health care, such as the epidemiological, psychosocial, sociological, economic, systemic of Neuman, cognitive medicine or ecological, ayurvedic, supraparadigmatic among others. All of them are seeking to combine one or more elements to integrate a model of health care. The article presents a systemic approach to health care with complementary medicines such as rehabilitative acupuncture, homeopathy and chiropractic through the application of a method of holistic care and integrated approach.

Materials and Methods: There was a participatory action research in January 2012 to January 2013, with a comprehensive approach in 64 patients using the clinical method. We included the environmental aspects, biological, emotional, and behavioral to identify, recognize and integrate the form of manifestation of the disease. Later, it was ordered in a coherent way the etiologic factors, precipitating factors and identified the vulnerability of the patients as well as the structural alterations, classifying them in immediate, mediate and late. Referred to the three disciplines: rehabilitative acupuncture, homeopathy and chiropractic to be seen doing references and against-references between them, evaluating the current state of health and each meeting by noting the clinical and behavioral changes submitted and thus the area of attention to which would be forwarded to continue their treatment.

Results: 64 patients rotated by the 3 areas taking an average of 30 meetings with rehabilitative acupuncture, 12 with homeopathy and 10 with chiropractic. The changes were submitted clinical attitudinal, behavioral, clinical and organic.

Conclusions: The model of care was multifaceted and interdisciplinary with a therapeutic approach of individualization and a holistic view to carry out a comprehensive diagnosis and provide quality health care to the population.
\end{abstract}

Key words: Model of health care, complementary medicine, approach holistic, health, disease.

\section{Introduction}

This paper is a proposal for the integration of a holistic health care method, taking into account the philosophical approaches in alternative medical practices, such as rehabilitative acupuncture, homeopathy and chiropractics, to maintain a state of well-being in individuals. Health protection, the paper argues, requires definite strategies to strengthen, widen the struggle against health oriented risk factors, and to promote a healthy culture. It also implies developing opportunities for choosing and practicing healthy lifestyles, and adequate provision of medical attention using different techniques, already in existence to restore sick individuals to a healthy state (Rodríguez-van Lier et al, 2011). At present, medical practice has been greatly diversified. Division of labor, high-tech specialization, is at its peak in medical practice. Given the diversities in enhanced approaches to medical practice/s, achieving a systemic insight into human organisms has become an arduous, or almost an insufficient, task.

These widening divides witnessed through the need for specialization, leads increasingly to a takeover by partial, fragmented approaches to the organism, which hinder a proper understanding of humans as complex entities.

Specialization is a distinctive characteristic of our time bringing, within our reach new techniques and knowledge without which many patients would not survive [Viniegra, 2005]. But it has deepened medical knowledge in a fragmented way. Since the concept of health is a multi-dimensional phenomenon, partial solutions are insufficient. Up to now, articulating this specific knowledge has been a major setback of this approach.

Due to diverse medical practice approach, the sum of the prescriptions of various specialists, in their evaluation of patients with several functional alterations manifest as different pathologies, fostering the consumption of a large sum of drugs, referred to as poly-pharmacy. These drugs are expensive, and most times, presents with negative effects on health. Existing health care models are based mainly on the analysis of the structure, processes and results of services, in addition to an organized health care system. These models are centered on the supply and use of services, and are limited to basic health demands of a given population (Ruales, 2004). Little attention has been given to complementary therapeutic models, which are necessary not only to reduce medical costs (Guthlin, 2005; Trichard, 2005), but also to enrich existing practices with preventive practices, in order to improve health and the quality of human lives; as well as to improve the level of empathy in the doctor-patient relationship, and make the right diagnosis, reducing the risk of developing (secondary), effects in medication (López et al, 2004).

This is the reason that necessitates the need for advancement in areas of specialization with an integrated systematic approach. Given the importance of health care in most countries, updates in models become necessary through the adoption of current global trends in specific fields. What is required in this approach is simple, complete, dynamic, and useful system in combating a complex reality, with emphasis on its constituent elements. 
http://dx.doi.org/10.4314/ajtcam.v11i1.29

From a systemic integrated, standpoint, the health care model must be all encompassing on different specialties, through an inter, and/or multidisciplinary framework, in order to preserve and improve the quality of lives through an enhanced interaction with, and preservation of, the natural environment (Lara, 2008).

A health care model corresponds to the content of health care itself and to the characteristics of the user/provider relations, such as the degree of accessibility and acceptability of services; the orientation of services in relation to persons, families and communities, the role played by persons, families and communities in their own health care (Ruales, 2004).

Lasting interpersonal relations are fundamental in order to facilitate care within any given model, besides the following characteristics:

1. A holistic approach centered on the person and his/her environment as a whole.

2. Personalized knowledge about the patient by the health care provider.

3. Warmth and empathy.

4. Mutual trust between the patient and the health care provider.

5. Participation of the patient in the decision making process (Ruales, 2004).

\section{The Concept of Health and Illness}

According to the definition of health within the holistic-humanist conception, an organism must maintain individual autonomy, and be able to become integrated harmoniously within a system. This ability must be related to the individual's flexibility to maintain a dynamic or homeostatic balance. The concept of illness is the result of the inability of the patient to integrate experiences [Capra, 1983].

Illness is an imbalance, or organic weakening of the individual's response to biological, physical, and chemical aggression. In order for the individual to become healthy, he needs to re-examine his behavior, his values, his social interaction and way of life. The more the illness is internalized, the more radical, the process of regaining health will be. Following this approach, illness is an opportunity to examine the meaning and orientation of one's life (Cibanal, et al, 2003) in order to attain resilience.

From the homeopathic point of view, illness in its essence is not recognized as an isolated event, instead it is considered as a disturbance affecting the person as a whole, expressed through symptoms. Accordingly, what is fundamental is not the existence of a given illness, but the individual who undergoes the suffering. Therefore, when an ailment appears, that's not really what counts, but rather the person who endures it (López, 1999).

Symptoms are the manifestation of altered homeostatic mechanisms, as a response of the neuro-endocrine immunological system's integrating function. If this occurs frequently, it activates diverse mechanisms, as part of a process known as allostasis. This term, used by Sterling and Eyer in 1988, determines the organism's ability to stabilize through inward changes what allows it to adapt to external, or internal demands (Carulla, 2004; Dvorkin, 1998) as an activated adaptive mechanism that re-establishes balance, trying to restore affected functions. According to Carulla 2004, the purpose of allostasis is to produce diverse biological mediators, such as cytokines (components of the immunological system), catecholamines (neuro-endocrine system), supra-renal steroids (endocrine system), tissue mediators and immediate response genes.

When the response is efficient and occurs in a brief time the body adapts and re-establishes homeostatic equilibrium or protects from damage; but when allostatic response mechanisms are constant and prolonged, it becomes excessively repetitive, or deactivate inadequately, hence, a so called allostatic charge is produced. This causes organic damage, and wear-out systems, and natural response mechanisms, provoking a lasting homeostatic imbalance which is generally known as illness (Carulla, 2004). Acute cases appear as congestive, hyper-reactive processes, excesses, etc.; when they are constant and prolonged, these states exhaust the organism_within as a chronic process which will appear as a deficiency, a weakness or a lack. For this reason, the symptom should not be silenced using substances which produce the opposite effect to reverse the symptoms, rather than the cause of the illness. Care professionals must identify the inability, the limitations or obstacles of the organism which hinder the effectiveness of the natural defense mechanisms (homeostatic processes) involved in the psycho-neuro-immuno-endocrine system (PNIE).

The interrelation between mental processes and the organism's regulating mechanisms requires an integrative approach. Thanks to PNIE, which is an important tool, health recovery is facilitated, since it integrates physio-pathological concepts and emotions.

Emotions are personal patterns of expressive behavior and each one of them is associated with a particular scheme of physiological activation, a cognitive-subjective experience and a specific neuro-anatomical substrate. The importance of emotions has been underlined in relation to the adaptive function for the individual's survival. An emotion is a multidimensional experience with at least three response systems: cognitive-subjective, behavioral-expressive and physiological-adaptive.

When imbalance occurs, the three response systems appears as an emotional response is triggered, provoking pleasant, or unpleasant sensations (Piqueras et al, 2009), altering the endocrine, immunological and nervous systems and making the organism vulnerable to the development of illness.

\section{The Relation between Matter, Consciousness and the Environment}

From Galen's times to the present, it is well known that emotions disturb the individual's health. In spite of this situation, modern medicine carry-out medical practice treatment of the mind, and the body, or the biological part as two totally independent and distant systems (Mocoso, 2009). Apparently, models of health care related to the mind and body are reflections of each other. According to Quantum Physics, when the observation of a certain particle or structure is too close, it becomes very difficult to tell whether one is looking really from the outside or the inside. Material structures converge with inter-connections and co-relations, forming a network. The brain also operates with inter-connections and co-relations. Thus, there are two sets of co-relations and there are co-relations between them (Capra, 2002).

There are four systems communicating with each other permanently, processing information, blending matter and energy together, there is an interaction between humans, and the environment (Rodriguez-vanLier et al, 2011). These systems in the mind means the immune system, the endocrine system and the nervous system, altogether they become the Psycho-neuro-immuno-endocrinology (PNIE), system (Moscoso, 2009). This theory well explain multi-directional interactions between the mind and body (González-Méndez, 2009), and the environment in molecules, cells and organs, which can have a direct impact on health and the quality of life of the individual and on the systems involved.

Taking the concept established by Díaz in 2007, of the body as a "psycho-physical system which is able, in an autonomous way to "capture (feel), decode (perceive), store (learn), elaborate (conceptualize, reason, understanding), symbolize (think, speak), evaluate (feelings, emotions, love), and emit (act), information from and to the environment towards the self, through behavior". We envision the human body not as an obedient structure anymore, but as a multi-directional co-relation, a true and unique mind-body essence; a monistic conception of the mind-body relation, which at present philosophers and neuro-lingüists are taking up again more strongly as bodily nature (corporeidad) (Díaz, 2007). The health-illness process is 
http://dx.doi.org/10.4314/ajtcam.v11i1.29

affected by internal (mind-body), and external agents (environment), which render complex the balance that must exist between the nervous, endocrine and immunological systems to keep the individual healthy, enjoying a good quality of life. We must take into account that biological systems are open, dynamic and changing, and behave in a dialectical and dialogical way without following the laws of linear causality. These characteristics make the systems practically unpredictable, being as they are complex systems (Rodríguez, Rodríguez, 2009).

\section{Integrative or Holistic Health Care Model}

It is important to define the concept "holistic" to be able to understand what an integrative model is. The root holon means "whole," "full," "entire", "complete" and the ism suffix means practice or doctrine. Holism, rather than a doctrine, is the reflection of investigation, understanding as an integrating way of life and knowledge which emphasizes the evaluation of events from the point of view of the body as a whole being within its context, going from the personal level to the global level. Hurtado, 2008, mentions that "the holistic perspective implies overcoming paradigms in order to favor the figure of syntagma, understood as an integration of paradigms. A syntagmatic attitude presupposes the convergence of diverse perspectives, which can only be achieved with holistic criteria" (Hurtado, 2008).

The syntagmatic attitude favors convergence, knowledge, openness toward other ways of focusing on things, by applying holistic criteria. "Overcoming paradigms" means that we have to know them study them, and integrate them into broader concepts.

Thus, the paradigm is implicit in the syntagma, which integrates a set of events into a whole with a unifying sense, where each event has a value due to its relationship with another event of the holos. A syntagm can be seen as an integration of paradigms of knowledge, a process emerging in different ways from diverse events and circumstances with a dynamic criterion. In other words, the holistic approach puts into action the syntagm, as the integration of paradigms, as ways to perceive a complex reality; the syntagm, in turn is the holistic understanding of an event, considering the context and the open system in which the event takes place (Hernández, 2005).

The principles of unity of the whole, simultaneity, synchronicity, completeness, of open possibilities, of complementarities as well as the principle of becoming one, are some of the holistic principles that allow one to represent an integrative model. In order to understand an integrative model it is fundamental to know the new contributions and proposals of the diverse paradigms, as well as their diverse techniques and methods. But what is most important is to have an open, flexible and creative attitude (Rodríguez, Rodríguez, 2009).

The integrative or holistic health care model is characterized by centering on "the whole" that makes up the individual and not on one of his/her parts. It goes beyond the simple manifestation of symptoms, which are reflections of a functional alteration or organic damage, as a result of a systemic alteration of the material, energetic and psycho-social part of human beings. The model supports the observation of each aspect of the individual: mind, body and soul, regardless of the apparent symptoms (symptomatic). It means to treat a person taking into account all the aspects of physical and mental health for re-establishing his/her health and allowing the expression of his/her autocratic vital principle endowed with reason, and the attainment of the highest goals of his/her existence as well as of societies and the natural environment (Hahneman, 1999).

\section{Proposal of an Integrative Method with Complementary Medical Practices}

At present, the concept of health includes integrated/holistic physical, social and psychological well-being. Therefore, well-being does not depend only on individual activity, but also on community action which allows, through sanitary strategies, the inclusion of diverse socio-cultural, and educational aspects, in the different social spheres, from the local to the national and global (Hernández, 2002). The complementary medical care model emerged because of two main factors: first, the need to approach the patient broadly, involving the environmental, biological, emotional and behavioral aspects which produce illness in order to respond to the needs of a country, such as Mexico, where specialized care causes poly-pharmacy; and, second, the elevated costs of medical drugs making them unavailable to most people.

Within the care model itself, it is important to identify, recognize and integrate the way illness appears in the individual; to order in a coherent way the diverse etiological (environmental and individual), factors that produce it, the agents that modify, maintain or eliminate it; to understand the imbalances that appear. Idiosyncrasy is the way in which illness appears in each individual and social group; according to their vulnerability or susceptibility, it will determine the way the triggering factors will affect them.

According to Dvorkin, there are two basic responses vis a vis an alteration: the cortico-supra-renal, or passive response and the sympathetic adrenergic, or fight response. These bodily chemical responses are initially elaborated by each individual mental processes and, in turn, can broaden or limit the neuro-chemical and bodily response (Dvorkin, 1998).

These emotional, cognitive and psychosocial resources which generate thoughts, feelings and actions are the so-called coping patterns, with which a person confronts the situations that affect an individual (Della, 2006). If this response is assertive, the person will, no doubt, solve adequately the situation at hand. Otherwise he/she will face a fairly long process. The individual as an open system is susceptible of being resilient insofar as maintaining his/her state of dynamic equilibrium or homeostasis thanks to energy exchanges of matter and information with the environment, because s/he has the property of auto-eco-organization, with entry ways to take from the environment the necessary elements to survive, keeping the interrelations and emerging processes required for this regulation process, and maintaining in this way a state of well-being (Rodríguez-vanLier et al, 2011).

Self regulation processes are given by the PNIE system, in which the mind, as a functional part of the brain, and the nervous, endocrine and immune systems have receptors in the cells, for information within and those without through the other systems by means of the messenger molecules. Therefore, under normal conditions, these four systems interact harmoniously, having as a result a state of homeostasis. This "state of homeostasis" promotes a state of health or well-being and prepares the organism for the constant struggle against the different internal and external factors which produce illness. A great number of factors, such as environmental, emotional, hereditary, personality traits, lifestyles, influence these interactions within this extremely complex process. Illness is translated as the loss of homeostatic equilibrium or as a failure in the mechanisms of regulation of homeostasis, which represent an interruption or a disturbance in the interaction processes of these four systems, as the onset of symptoms which characterize a pathogenic condition or an illness (Moscoso, 2009).

The first system that becomes altered is "the mind" where the spiritual part of the individual resides, with changes in the will, the intellect and feelings, expressed through modifications in behavioral and cognitive functions (modifications in the energetic part). If, during this process, regulating and homeostatic mechanisms are activated (feedback and PNIE), the individual reverts to a state of well-being, without greater consequences; otherwise, if these mechanisms are not sufficiently able to carry out their functions, structural modifications will occur (altering the matter) producing consequences that go from immediate to delayed, represented by acute, chronic and chronic-degenerative illnesses, which in turn will affect these sub-systems and the individual's environment (Figure 1). Therefore, human beings are a whole entity, integrated by body, spirit and 
http://dx.doi.org/10.4314/ajtcam.v11i1.29

consciousness which can be considered healthy when all its sensations and reactions maintain a harmonious balance, controlled by energetic processes (which Samuel Hahnemann, called "vitality"). This vital energy enables the organism to react to the healthy and pathogenic stimuli from the environment (López, 1999).

To find the factors that produced the bio-energetic (energy), and/or structural (matter), imbalance an exhaustive anamnesis is carried out, emphasizing the environmental, behavioral, emotional and cognitive aspects of the individual. A physical examination is also made, in order to determine biologic changes, establishing the weaknesses and strengths in each area of the patient (comprehensive diagnosis), since the individual visits the doctor due to a particular discomforting symptoms and not considering the organism as a whole, keeping in mind that the individual is a whole involves body and mind, in relation to the environment. Therapies that reactivate the natural defense mechanisms of the organism (neuroendocrine and immunological mechanisms, not only for defense but also for recognition and maintenance), such as homeopathy, rehabilitative acupuncture and chiropractic, involve structured models to analyze the individual from its different constituent sub-systems in order to re-establish harmony, bio-energetic homeostasis and the natural regulating mechanisms of the body and, through these, regain health (Figure 2).

\section{Clinical History}

It is very important to keep track of the individual patient in order to reach the cause of the disease; that is why the clinical history is very useful to the clinician. Clinical history is a legal document through which the first contact between a health professional and a patient is established, where the necessary information for health cares is gathered. Information is obtained following the semiological clínical method through different

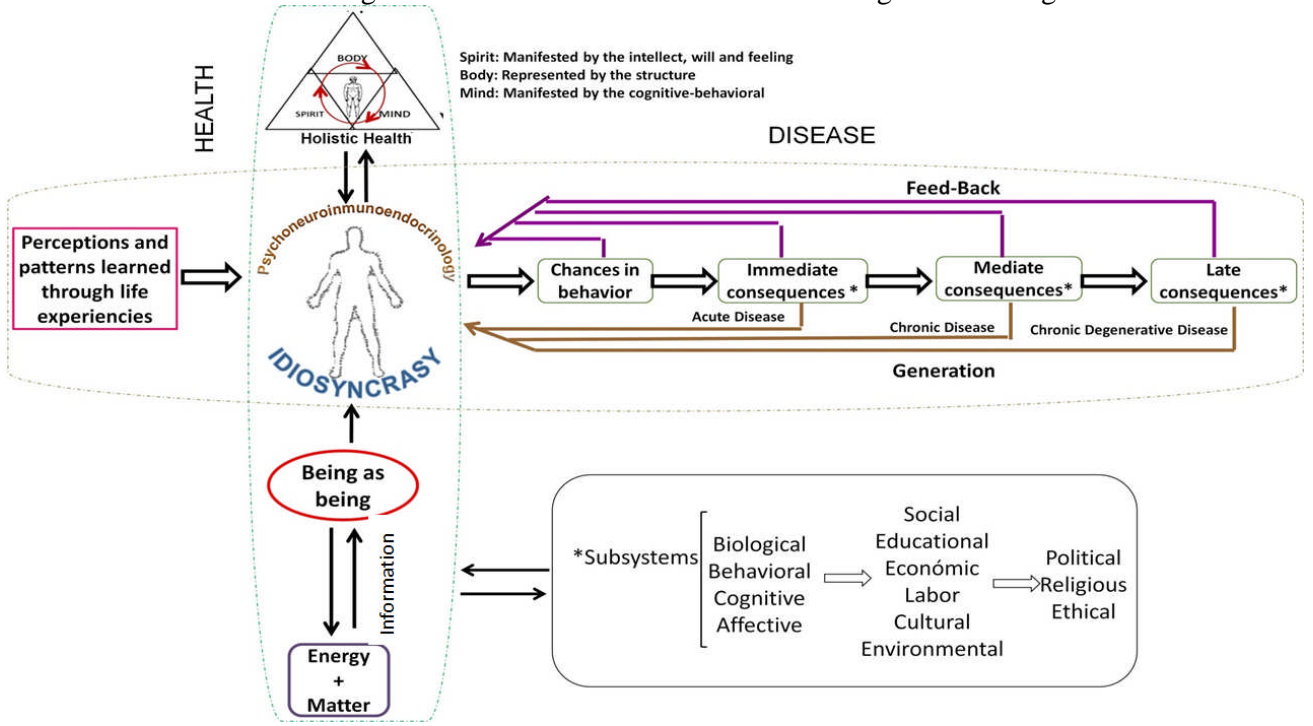

Figure 1: Homeostatic Mechanisms Regulation of the Human body.

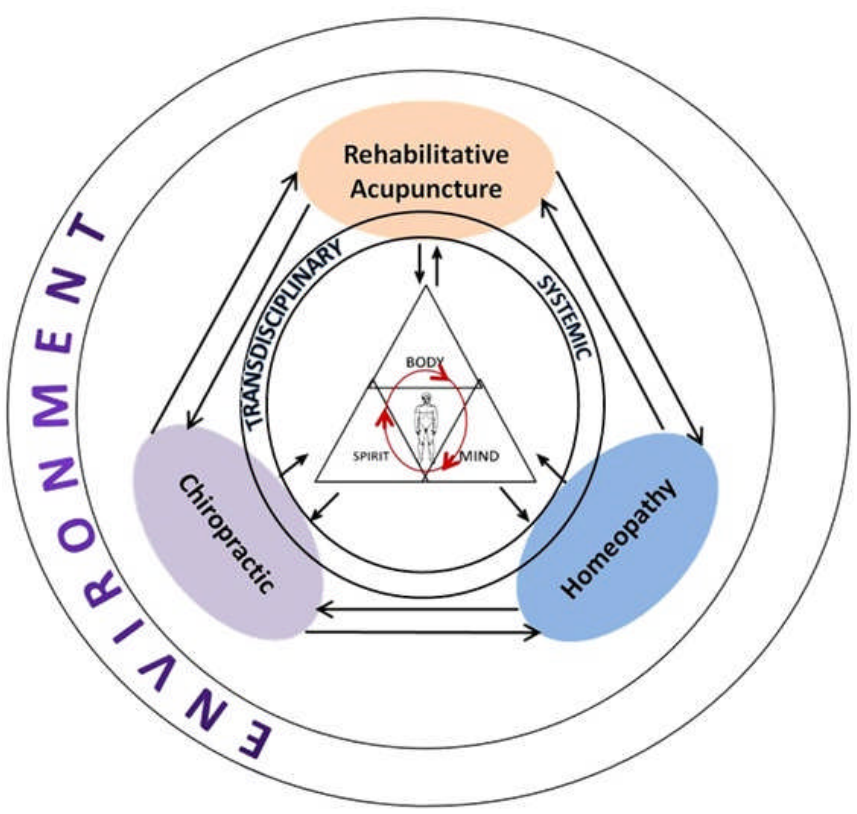

Figure 2: Comprehensive, and Systemic Approach to Health Care with Complementary Medicines. 


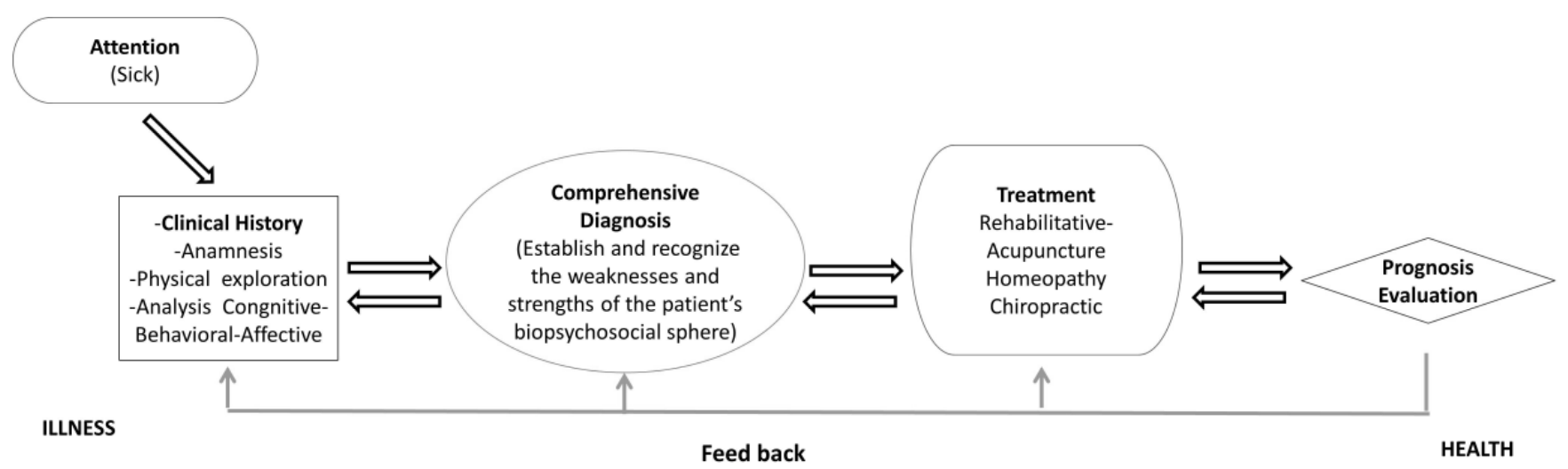

Figure 3: Method Based on Complementary Medical Practices.

ways. Anamnesis helps to identify where the functional problem presented by the patient is located, together with predispositions due to the patient's hereditary-family background, vulnerability to illness because of his/her lifestyle, climactic and environmental circumstances. Through anamnesis we identify the level of the functional problem, through physical exploration we identify the degree of the structural problem presented by the patient.

Cognitive--emotional-behavioral analysis helps to know the individual's behavior in his/her environment, that is to say, looks into the consequences of past behavior, which are responsible for current behavior [Yáber, 1993]. The perceptions, opinions, beliefs and feelings towards an object or person are examined, as well as information about the context that generates attitudes. Besides, the tendency to react to objects in a certain way (attitude) is explored. Attitudes are determinants of behavior, since they are tied to perception, personality, motivation and predisposition, and provide the emotional support for interpersonal relations and identification with the environment (Figure 3).

\section{Rehabilitative Acupuncture}

The advantages of the Rehabilitative Acupuncture are many; it promotes changes not only in sensorial functions, but also in locomotive functions that can be autonomous or psychological. The results can be observed as visceral changes, hormonal and immune response and also behavioral changes. Those are results that are reached through neuro-modulation and that is the reason why nowadays, its mechanism is considered to be better explained through psycho-neuro-immune-endocrinology (Clemmons, 2004; Cho, et-al, 2001, Noris, 2003). Abnormal functions of tissues and organs are repaired through neurologic and humoral involuntary responses. The stimulation of Rehabilitative Acupuncture activates brain conexions with repercussions such as autonomic, endocrines and immunes to recover homeostasis. Adaptive responses are generated establishing a higher level of homeostatic organization, in order to become restorative physiologic influences (Clemmons, 2004; Cho, et-al, 2001). Prevailing alterations of the body functions (physiopathology), according to the individual's clinical history of pathology are identified together with the environmental factors related to the disease and analyzed together.

\section{Homeopathy}

Homeopathy as a discipline requires several points of view in considerig the resolution of the patient: homeopathy supports the identification of how the organism is affected by disease, with the proposal that disease would be the product of hyper-, hypo- or degeneration of functionality (that in turn can be self destructive or only function distortive). Observing the physiopathology from multiple diseases where the functional interrelated behaviors generate disease by modification or lacking of control in the compensatory mechanisms, altogether affecting homeostasis. Homeopathy also takes into consideration the mental aspects from the individual and such approach is of vital importance, since the modern holistic trends, rescue the important concept such as: "mind and body as a unique essence" [Damasio, 2006], as a consequence the body, being the residence of cognitiveemotional manifestations through neurochemical changes generated by different events, in the end becomes altered.

The above biologic behaviors are going to modify the psychic behaviors, with consequences to the body, that are controlled by the modulation of the second messengers such as; chemical neuro-transmissors, cytokines and hormones. All kinds of repetitive conduct that modifies and deteriorates the patient quality of life as much as his/her immediate environment is considered a mental symptom. Homeopathy, preponderates the management of the patient using its characteristic remedies of natural origin, obtained from animal vegetal and mineral sources; besides anamnesis emphasizes the attention not only to the patient' circadian rithm but also considers chronobiology itself by considering the time schedules of aggravation or improvement of the symptoms, altogether with influences from the environment, weather conditions related and from the geographic and atmospheric nature. All the above considered in concurrence, constitute the essential postulates of Homeopathy's philosophy: therapeutic approach individually and personally designed. 
http://dx.doi.org/10.4314/ajtcam.v11i1.29

Chiropractic

Chiropractic is a therapeutic approach that characteristically prevents, and rehabilitative; it is not toxic, given the advantage of a patienttherapist close and personal interaction. This kind of therapy is efficient in acute or chronic maladies, some of which are even spectacular due to the direct, and indirect action exercised up on the functional state of the patient, particularly the ones affecting skeletal muscle (Went 1958).When the individual experiment stress, anguish, tension, anger, physical burning, acute or chronic pain, its organism develop a defense mechanism to face such adverse context by manifesting muscle spasms that elicit sub-luxation of the spinal bones, some of them negatively impact health since they produce a self-traumatic action targeted to any body organ or section of the organism, modifying the correct body function that may exacerbate or moderate the morbid condition (Lipton, 1999). It is right here where chiropractic comes to help, because the therapist should be capable to detect, analyze and therefore help correct vertebral mispositions. Chiropractic helps restore the bio-mechanic and spinal equilibrium that influenciate the skeletal muscle, neurologic and vascular systems in the organism. Direct manipulation is the main treatment method which takes advantage of the vertebral spine to eliminate mechanic tension affecting the columnar discs, articulations in general, nerves and the spinal cord. Majority of the patient discomforts are corrected when the therapist performs corrective adjustment of the spinal cord and this action allows the energetic blood circulation to communicate between the brain and organs. A mechanic action exercised up on the vertebral disc, and posterior articulations, disengaging over-folding of the affected articulation capsule (that makes the characteristic acute sound), and in the end the reflex action over the muscle induces what is illustrated by diminish, or banishment as para-vertebral and ligament and tendon contractures. Such contractures are sensitive to oppression and exacerbation of them induces homonymous muscular control (Went 1958).

Important it is, to mention that in order to obtain good results with the proposed model for Preventive Health Care, integrating Rehabilitative Acupuncture, Homeopathy and Chirropractic, becomes indispensable to recluse and count on: 1) licensed and certified professionals in each area of health care, that would be the therapists and also physicians with medical specialties; and 2) since the purpose is to promote an integral health care model of attention, is important that complementary medicines are centralized in a single unit of health care attention, able to offer human resources with formation of each area in such a way that a network of communication for inter-consultation, and collaboration will spontaneously become integrated and all the therapists can count on each other to integrate a professional team that together help provide better, more efficient and systemic health care attention absolutely focused on the patient. The above is the conception of a Clinic of Preventive Medical Attention whose main purpose is to preserve and help improve health for majority of the population in developing countries.

\section{Conclusions}

The proposal of a Model of Preventive Health Care Attention, based on three main alternative medicines such as Rehabilitative Acupuncture, Homeopathy and Chiropractics, present an integrated method of health care with a therapeutic focus of individualization that helps maintain an empathic relationship between patient and therapist with an inclusive holistic vision whose main goal is to perform an integral diagnosis and therefore better select the correct treatment in every particular patient. All these three therapies keep a vision in common, their main objective is to reestablish health and reintegrate the individual to the bio-psychosocial sphere that originated the individual, and hopefully accompany him/her through the process of resilience so the homeostatic equilibrium is finally recovered. Another main goal for the proposal is to enforce the preventive policies for health care, improve the efficacy; efficiency and safety of modern medical practices incorporating these policies to the prevention of disease, preservation of health, providing healing and integral rehabilitation minimizing adverse reactions while keeping the budget for health financially affordable.

\section{Acknowledgments}

The authors are very thankful to Josefina Ramirez, Emma Lopez-Espinosa for their contributions to this manuscript. We also give thanks to Jesus Alvarado for her assistance in the preparation of the manuscript.

Disclosure Statement: No competing financial interests exist.

\section{References}

1. Capra F. The hidden connections: integrating the biological, cognitive and social dimensions of life into a science of sustainability. New York:Doubleday, 2002.

2. Capra F. The Tao of Physics, 9th. España:Sirio,1983, 64-68.

3. Carulla S. Tratado de Longevidad. Sao Paulo: Panamerican, 2004.

4. Cibanal JL, Arce SMC, Carballal BMC. Relación de ayuda y técnicas de comunicación en ciencias de la Salud]. España:Elsevier, 2003:266267.

5. Clemmons, R.M. What's Acupuncture: Scientific Basis. In: Veterinary Acupuncture. Mixed Practice Class \#8, Session 1. The Chi-Institute. 24 al 27 de june de 2004. Gainesville, Florida, EUA.

6. Cho, Z.H., Wong. E.K., Fallon, J. Neuro-Acupuncture. Neuroscience Basis. Q-puncture, Inc. los Angeles, Califórnia, USA. 2001.

7. Della Mora, M. Estrategias de afrontamiento en adolescentes embarazadas escolarizadas. Revista Iberoamericana de Educación 2006, 38:3. [Viewed 2011 September]. Available at: http://www.rieoei.org/deloslectores/1342Mora.pdf 
http://dx.doi.org/10.4314/ajtcam.v11i1.29

8. Damasio, A. El error de Descartes, la razón de las emociones. Ed. Destino, ISBN 9788423346165, España, 2006.

9. Díaz JL. La conciencia viviente. México: Fondo de Cultura Económica, 2007.

10. Dvorkin R. Bases fisiológicas de la práctica médica, 5th. Argentina:Panamericana, 1998.

11. González-Méndez TM. Psiconeuroinmunoendocrinología. emociones y Enfermedad. MedULA 2009;18:155-164.

12. Guthlin C. The cost-effectiveness of homeopathy: the perspective of a scientist and mother. Homeopathy. 2005; 94(1):1-2.

13. Hahneman S. Organon de la Medicina. Reviewed by David Flores Toledo. $2^{a}$ ed. México:IPN, 1999:141.

14. Hernandez R. Epistemológia y formación gerencial: un enfoque holístico. Negotium 2005;1(1): 3-11.

15. Hernández, J. Bioética General, Manual moderno: México, 2002.

16. Hurtado BJ.¿Investigación holística o comprensión holística de la investigación?. Revista Internacional Magisterio. Educación y Pedagogía 2008;3:20-27.

17. Lara LE. El modelo de salud en México. [monograph on the Internet]. Firma Milliman Global, México 2008 [Viewed Abril 13 2010]. Available at: http://latinamerica.milliman.com/perspective/publications/pdfs/El-Modelo-De-Salud-En-Mexico-INT.pdf

18. Lipton BH. The development of the Science of Chiropractic Philosophy. Today's Chiropractic. 1999:20-31.

19. López EJA. Notas para la historia de la homeopatía]. Rev Cubana Med Gen Integr 1999;15(5):587-90.

20. López GV, Rodríguez PM, Treviño GC. Complementary and Alternative Medicine. Medicina Universitaria 2004;6(25):264-71.

21. Moscoso MS. De la mente a la célula: impacto del estrés en Psiconeuroinmunoendocrinología. Liberabit 2009;15:143-152.

22. Noris, M. The Biological Mechanisms of Acupuncture. IN: 29th International Congress on Veterinary Acupuncture Proceedings. 20-23rd August, 2003. Santos, SP., Brasil. Pp. 83-92. 2003.

23. Piqueras RJA; Ramos LV; Martínez GAE; Oblitas GLA. Emociones negativas y su impacto en la salud mental y física. Suma Psicológica, 2009, (16)2:85-112.

24. Rodríguez RR, Rodríguez PJ. Psiconeuroinmunoendocrinología (PNIE), el Pensamiento Complejo y la Medicina Naturista. Medicina Naturista 2009;(3):2:86-91

25. Rodríguez-vanLier ME, Henández SLM, López-Espinosa E. La salud desde una perspectiva holística. Verbatim memories, VI International Conference on Electromechanics and Systems Engineering, 2011 oct Mexico, D.F., México.

26. Ruales J. Panel: Tendencias en Servicios de Salud y Modelos de Atención de la Salud. National School of Public Health, 2004;22:33-39.

27. Trichard M, Chaufferin G, Nicoloyannis N. Pharmacoeconomic comparison between homeopathic and antibiotic treatment strategies in recurrent acute rhinopharyngitis in children. Homeopathy. 2005; 94(1): 3-9.

28. Viniegra VL. La práctica de la medicina: Situación actual y perspectivas. [monograph on the Internet]. México:Faculty of Medicine, UNAM 2005. [Viewed June 23, 2006]. Available at: http://www.posgrado.unam.mx/publicaciones/ant_omnia/15/05.pdf

29. Yáber, G. Análisis conductual y el bienestar de la humanidad: Profesión y metas. Carta semanal, 26, 6:1993.

30. Went H, Walter R, The mechanism of action of chiropractic. Arch Orthop Unfallchir 1958; 49(5):480-5. 